\title{
A IMPORTÂNCIA DO DESENVOLVIMENTO DE ASPECTOS SOCIOEMOCIONAIS PARA A GESTÃO DO CONHECIMENTO NAS ORGANIZAÇÕES
}

\author{
THE IMPORTANCE OF THE DEVELOPMENT OF SOCIOEMOTIONAL ASPECTS FOR THE \\ MANAGEMENT OF KNOWLEDGE IN ORGANIZATIONS
}

\section{LA IMPORTANCIA DEL DESARROLLO DE ASPECTOS SOCIOEMOCIONALES PARA LA GESTIÓN DEL CONOCIMIENTO EN LAS ORGANIZACIONES}

Cibele Pacheco Gomide. Universidade São Judas Tadeu. E-mail: cibgomide@gmail.com

Antônio Fernando Gomes Alves. Universidade São Judas Tadeu. E-mail: prof alves@uol.com.br Agência de fomento: Universidade São Judas Tadeu

\section{RESUMO}

A sociedade já se deu conta de que a produção intelectual gera mais riqueza que a industrial, contudo, os profissionais continuam a enfrentar barreiras para implantar as práticas de GC (Gestão do Conhecimento), a maior das quais talvez seja a dificuldade em criar um ambiente propício à geração de conhecimento e ao compartilhamento. A partir disso, 31 profissionais do conhecimento foram questionados sobre se os aspectos socioemocionais impactam a GC, tendo $97 \%$ deles concordando em que esses aspectos impactam as práticas de GC. Todavia, apenas $19 \%$ já implantaram algum tipo de ação para o desenvolvimento de habilidades socioemocionais, sendo a falta de conhecimento suficiente sobre o assunto a principal justificativa apontada pelo gestor e ou a alta gestão. Dessa forma, este artigo salienta a importância de aprofundar a questão e munir esses profissionais de conhecimento e ferramentas para o melhor desenvolvimento das práticas da gestão do conhecimento, tão valioso para as organizações.

PALAVRAS-CHAVE: Gestão do conhecimento. Barreiras à gestão do conhecimento. Habilidades socioemocionais.

\section{ABSTRACT}

Society has already realized that intellectual output generates more wealth than industrial, yet professionals face many barriers to the implementation of KM (Knowledge Management) practices, one of the biggest being people's difficulty in creating an environment conducive to knowledge generation and sharing. From this, 31 knowledge professionals were questioned about whether socioemotional aspects impact the KM, and 97\% agree that these aspects impact KM practices. However, only 19\% have already implemented some type of action for the development of socioemotional skills, the main justification consulting in the lack of sufficient knowledge on the subject by the manager and / or top management. Thus, this article stresses the importance of future studies to go further into the provide these professionals with knowledge and tools for the best development of knowledge management practices, such valuable asset to organizations, at large.

KEYWORDS: Knowledge management. Barriers to knowledge management. Socioemotional skills.

\section{RESUMEN}

La sociedad ya se ha dado cuenta de que la producción intelectual genera más riqueza que la industrial, sin embargo, los profesionales continúan enfrentando barreras para implantar las prácticas de GC (Gestión del 
Conocimiento), la mayor de las cuales tal vez sea la dificultad en crear un ambiente propicio a la generación de conocimiento y al compartir. A partir de eso, 31 profesionales del conocimiento fueron cuestionados sobre si los aspectos socioemocionales impactan a la GC, teniendo el 97\% de ellos concordando en que esos aspectos impactan las prácticas de GC. Sin embargo, sólo el 19\% ya implantó algún tipo de acción para el desarrollo de habilidades socioemocionales, siendo la falta de conocimiento suficiente sobre el asunto la principal justificación apuntada por el gestor y la alta gestión. De esta forma, este artículo subraya la importancia de profundizar la cuestión y proveer a estos profesionales de conocimiento y herramientas para el mejor desarrollo de las prácticas de gestión del conocimiento, tan valioso para las organizaciones.

PALABRAS-CLAVE: Gestión del conocimiento. Barreras a la gestión del conocimiento. Habilidades socioemocionales.

\section{INTRODUÇÃO}

O entendimento não pode perceber e os sentidos não podem pensar coisa alguma. Somente quando se unem, resulta o conhecimento (KANT, 1974).

Conhecimento é o resultado da interação do homem sobre o mundo, as coisas, as pessoas. Segundo Corrado e Hao (2014), os investimentos em ativos intangíveis na gestão do conhecimento foram o fator decisivo no crescimento e desenvolvimento desde 1995 da economia americana, mais do que os investimentos em ativos tangíveis. A partir desse movimento, a sociedade se deu conta de que a produção intelectual gera mais riqueza que a industrial e, a partir disso, a gestão do conhecimento é parte fundamental da estratégia de crescimento e sobrevida de uma empresa (DAVENPORT e PRUSAK, 1998).

Contudo, apesar de as organizações precisarem abrir-se, tornar-se mais flexíveis e eficientes no processo de gestão do conhecimento para manter-se competitivas (DAVENPORT e PRUSAK, 1998), o capitalismo moderno continua tratando as pessoas como item descartável, desestabilizando assim os sentimentos de confiança e de cooperação, fundamentais na formação de laços sociais.

O capitalismo destrói os elos entre os seres humanos (SENNETT, 1999), o que levou este estudo a questionar: como estimular o compartilhamento de conhecimento em um ambiente hostil socialmente? Que modificações as organizações precisam promover em sua cultura para manter-se competitivas em uma realidade na qual o conhecimento é fonte de lucro que precisa ser compartilhado, a despeito da ainda enorme barreira da subjetividade humana?

A partir disso, pretende este artigo apresentar o conceito de Nonaka, Toyama e Hirata (2011) de que o conhecimento é criado por seres humanos, fato que inviabiliza a concepção de uma teoria de criação do conhecimento alheia à subjetividade humana, como pensamentos, 
sentimentos, ideias, motivações e sonhos. Espera-se contribuir com a sociedade do conhecimento trazendo luz à questão da importância do desenvolvimento de aspectos socioemocionais nas organizações como importante ferramenta à gestão do conhecimento.

\section{REFERENCIAL TEÓRICO}

\subsection{Gestão do Conhecimento}

Segundo Takeuchi e Nonaka (2008), o conhecimento acontece primeiramente na dialética ${ }^{1}$. A mente humana deve ser capaz de aceitar e confrontar ideias e informações contrárias simultaneamente para assim encontrar as melhores soluções. Além disso, o conhecimento é formado por elementos antagônicos: o conhecimento tácito e o explícito. O conhecimento explícito está no âmbito formal. É frequentemente apresentado de forma sistemática em números, dados, fórmulas, regras, manuais etc. Já o conhecimento tácito, ou implícito, está arraigado na experiência do indivíduo, suas ações, crenças, emoções e, por ser um tipo de conhecimento extremamente pessoal, é enorme a dificuldade de compartilhar essas experiências de maneira formal (TAKEUCHI e NONAKA, 2005). A partir disso, a sociedade vem-se mostrando interessada em desenvolver técnicas, modelos e métodos para estimular o confronto de informações diversas, objetivas e subjetivas, a geração de conhecimento, seu compartilhamento e valorização das organizações.

A partir da Revolução Industrial (século XVIII), houve esforços de eliminar o paradoxo, recortando as etapas dos processos de trabalho a fim de automatizá-lo e eliminar a possiblidade de o sujeito pensar e questionar ${ }^{2}$. No entanto, com a evolução das tecnologias, alterou-se enormemente a forma como as pessoas acessavam informações e construíam conhecimento (TAKEUCHI e NONAKA, 2008). O resultado disso se constata na velocidade inacreditável das inovações, no seu efeito exponencial no mercado e na mudança radical na relação do homem com o trabalho (WILLIAMS e BUKOWITZ, 2002; CAMANHO, 2016).

E para uma empresa gerar essa produção intelectual, importa propiciar uma "espiral do conhecimento" que traga à tona e articule o que é tácito e explícito, fazendo desse modo que

\footnotetext{
${ }^{1}$ Dialética é o modo de pensarmos as contradições da realidade, o modo de compreendermos a realidade como essencialmente contraditória e em permanente transformação (Konder, 1981).
} 
${ }^{2} \mathrm{Na}$ Revolução Industrial, o trabalho era mecanizado e contínuo. Se a função era incluir uma peça em uma máquina, era só isso que se fazia todo o dia, no mesmo ritmo e agilidade. A maioria não tinha conhecimento do produto final nem podia fazer qualquer questionamento sobre o trabalho ou suas condições (Takeuchi e Nonaka, 2008).

o que é subentendido, implícito, se torne explícito, formal, capaz de ser transmitido e a partir disso, esse conhecimento explícito pode internalizar-se e voltar a ser implícito. Logo, uma vez completada a espiral, o objetivo é reiniciá-la, agora em patamares superiores, para que a capacidade de criação de conhecimento na organização se amplie (TAKEUCHI e NONAKA, 1997).

Contudo, para movimentar a espiral do conhecimento, é necessário conhecer a as pessoas que fazem parte dessa organização, suas habilidades, como conseguem as informações, como utilizam, como criam e, principalmente, como esses conhecimentos são compartilhados e as dificuldades nesse processo, já que os membros do grupo, seus status sociais, hábitos e conhecimentos já internalizados pelas pessoas comprometem a recepção e interpretação das mensagens e podem constituir barreiras à gestão do conhecimento (BERLO, 1970, p. 53).

Além disso, embora as organizações sejam sistemas sociais baseados na cooperação entre as pessoas (CHIAVENATO, 2010), a "hostilidade em compartilhar o conhecimento é um fenômeno que domina a realidade organizacional amplamente" (SILVEIRA, 2011). Segundo Szulanski (2000), a falta de motivação à interação social e ao compartilhamento de experiências e conhecimento pode levar à procrastinação, rejeição, sabotagem, passividade, entre outras barreiras para a gestão do conhecimento.

Apesar das barreiras existentes à gestão do conhecimento, as empresas precisam ser capazes de construir uma inteligência coletiva em fluxo constante, isto é, o conhecimento precisa ser explícito e circular, alcançando patamares cada vez maiores. Contudo, para que as organizações alcancem esse objetivo, é preciso rever as estruturas rígidas e hierárquicas ainda presentes, bem como adequar-se às transformações inerentes às novas demandas dessa nova sociedade (REBELO et al., 2012).

\subsection{As Barreiras Subjetivas nas Organizações}


Para Drucker (1998), estamos na "Sociedade do Conhecimento", que demanda - para manterse competitivo - apreender o paradoxo, as polaridades, os diversos saberes pessoais, as oposições não como algo a ser eliminado, mas sim acolhido, cultivado e transformado em conhecimentos explícitos e coletivos (TAKEUCHI e NONAKA, 2008), já que o conhecimento mantido apenas com o sujeito não tem valor para as organizações, pois é perdido no seu afastamento (CHOO, 2003).

Choo (2003) complementa que o uso estratégico de informações permite criar novos conhecimentos por meio do aprendizado, o que possibilitará à organização desenvolver knowhow, novos produtos, processos e aperfeiçoar o que já existe. Além disso, a administração desse conhecimento e o desapego de antigas práticas vão garantir o aprendizado real na organização, sem o qual as empresas continuarão a "reinventar a roda desnecessariamente, por não serem capazes de localizar o conhecimento especializado que existia em algum lugar dentro da organização".

Para isso, cada vez mais posições dos mais diversos cargos estão se desenhando como "trabalhadores do conhecimento". Isto é, o conhecimento formal e técnico não é mais suficiente: cada vez mais se exige o desenvolvimento de "relacionamentos construtivos" com a equipe, fornecedores, clientes, com o mercado, atento sempre às próprias ações de forma crítica para ser capaz de modificá-las quando necessário (ARGYRIS, 2001).

Contudo, as organizações são capazes de aprender quando há uma mudança de mentalidade sobre o que motiva as pessoas, seus modelos mentais e a sua capacidade de produção. A transformação da visão sobre as mudanças é fundamental, visto que elas representam processos importantes para uma organização aprender. Em adição, os grupos têm de estar aptos a compartilhar e alinhar seus propósitos para que o foco e a energia sejam voltados a um objetivo comum, bem como à visão de uma realidade de inter-relações dinâmicas e não rígidas na dualidade causa-efeito (SENGE, 1995).

Para que o trabalhador do conhecimento consiga produzir conhecimento e compartilhá-lo, Nonaka e Takeuchi (1997) consideram que cabe à organização criar um ambiente propício. Os autores definem esse ambiente como "ba" ou "ambiente capacitante", uma combinação de espaço físico, espaço virtual, confiança mútua, valores, percepção de time e desafios compartilhados para que o conhecimento individual e/ou coletivo possa avançar. 


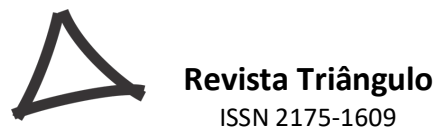

Contudo, muitas são as barreiras que atrapalham o funcionamento de toda essa estratégia. Por mais que as organizações procurem inserir práticas de gestão do conhecimento em seu meio, os entraves são enormes, talvez o reflexo de uma "tendência humana universal" em que quatro valores básicos fazem parte do planejamento das ações: preservar o controle unilateral; supervalorizar as vitórias e menosprezar as derrotas; reprimir os sentimentos negativos; e ser tão "racional" quanto possível - o que, em geral, significa definir objetivos claros e avaliar o próprio comportamento. Dessa forma, os profissionais evitam o aprendizado, e um dos motivos por isso ocorrer, até mesmo por conta da carência de habilidades para enfrentar sentimentos de fracasso. (ARGYRIS, 2001).

A carência em enfrentar os fracassos não se dá apenas em âmbito individual, mas também se estende às organizações. Em seu estudo, Argyris (2001) reproduz o testemunho de um CEO a esse respeito: "É lamentável, mas às vezes cometemos enganos e contratamos a pessoa errada. Se os profissionais não produzem e consistentemente se mostram incapazes de melhorar, não sabemos o que fazer, senão demiti-los."

A partir disso, os profissionais reagem defensivamente a qualquer cobrança, procuram culpados para se eximir de responsabilidade, retêm o seu conhecimento com medo de perder o poder e serem substituídos e geram mais custos por impedir a empresa de compreender e agir sobre os problemas de forma mais rápida (ARGYRIS, 2001).

Essa perspectiva enquadra-se em diversos estudos que apontam questões subjetivas como barreiras à gestão do conhecimento: a) desconfiança entre as pessoas; b) a relação com as posições das pessoas nos grupos; c) motivação a compartilhar experiências e conhecimentos; d) percepção do conhecimento como poder; e) falta de percepção de pertencimento à organização; f) medos de punição; g) relação com a cultura da empresa; h) falta de sentimento de reconhecimento; i) incompreensão dos objetivos da empresa e de suas atividades; j) dificuldade de administrar o tempo; k) falta de relação interpessoal; 1) falta de apoio das lideranças; m) resistência em usar os sistemas de informação disponíveis; n) resistência à mudança por medo e ansiedade; o) ameaça à especialização; p) medo de ser explorado; q) medo de tornar-se dispensáveis; r) medo de prejudicar alguém (BARROS, 2010; FLORIANO, 2009; REBELO, 2012; LEUCH et al., 2005; SILVEIRA, 2001; DAZA, 2003; MESQUITA, 2006; MATOS, 2010). 
Não é difícil constatar que muitas dessas barreiras referem-se às dificuldades das pessoas e dos grupos em se relacionarem de forma colaborativa em uma situação de organização pautada nos conceitos capitalistas de lucro a todo custo e do sucesso como único resultado esperado, bem como o sofrimento inerente a todo esse contexto.

Dessa forma, trazer luz aos aspectos subjetivos da gestão do conhecimento pode contribuir para que as organizações aprendam a lidar com os fracassos e questões socioemocionais individuais e dos grupos e - ainda mais importante - para que compreendam que não são questões a evitar, visto serem inerentes às relações humanas, o verdadeiro cerne da construção de um ambiente propício a uma interação de colaboração.

\subsection{Aspectos Socioemocionais no Trabalho}

A gestão do conhecimento depende de processos de socialização das informações (NONAKA e TAKEUCHI, 1997) razão por que é importante para o processo de conhecimento capacitar as pessoas a tornar-se socialmente habilidosas. Essa necessidade foi formalizada no Fórum Internacional de Políticas Públicas - Educar para as competências do século 21, realizado em 2014 no Brasil, de que participaram lideranças educacionais de vários países para compartilhar conhecimento e ressaltar a importância das competências socioemocionais para melhores resultados educacionais, sociais e econômicos. Todos os trabalhos apresentados durante o Fórum incluíram a noção de "educação integral e inclusiva",

que provê os alunos não apenas com informações e conhecimentos, mas os prepara para a vida por meio do desenvolvimento de diversas competências, tanto cognitivas quanto socioemocionais, cultivando os valores necessários para uma boa cidadania, como cooperação, responsabilidade e engajamento na construção de um mundo melhor (ABED, 2014).

Dessa forma, a discussão sobre a importância de olhar para os aspectos socioemocionais na educação básica é uma tendência atual definida pela nova sociedade, marcada como está pela velocidade das mudanças, pelos desafios socioeconômicos e pela necessidade de as crianças desenvolverem "uma resiliência que as protege de muitos dos piores efeitos de um ambiente adverso" (TOUGH, 2014).

Sobre a importância da resiliência, Catania (1999) colabora com a perspectiva de que, quanto mais socialmente habilidosa uma pessoa for, maior a probabilidade de obter reforçadores e, 


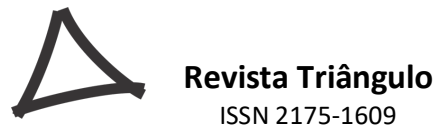

por consequência, ampliar seu repertório comportamental, favorecendo lidar com situações de conflito que claramente envolvem estimulação aversiva (medos, punições etc.), situações refletidas amiúde em qualquer organização, principalmente nos grupos que mais demandam interação social, como as organizações do conhecimento.

Del Prette e Del Prette $(1998,1999,2008)$ oferecem uma grande contribuição à literatura no que diz respeito ao desenvolvimento de habilidades sociais - o cerne, segundo os autores, da aprendizagem em âmbito escolar e, inclusive, a promoção de saúde mental. Ensinam os autores que, entre as habilidades de uma pessoa socialmente habilidosa, devem incluir-se: como fazer e responder a perguntas; gratificar e elogiar; pedir e dar feedback nas relações sociais; iniciar, manter e encerrar conversação; dizer "por favor"; agradecer; apresentar-se; cumprimentar; despedir-se; manifestar opinião, concordar, discordar; fazer, aceitar e recusar pedidos; desculpar-se e admitir falhas; encerrar relacionamento; expressar raiva e pedir mudança de comportamento; interagir com autoridades; lidar com críticas; refletir sentimentos e expressar apoio; falar em público; resolver problemas, tomar decisões e mediar conflitos; fazer amizade; expressar solidariedade.

Não obstante os estudos de Del Prette e Del Prette, inclusive as discussões do Fórum Internacional de Políticas Públicas - Educar para as competências do século 21, concentraram-se no ambiente escolar, os adultos provindos a partir de uma educação baseada na instrução técnica continuam carecendo das competências socioemocionais, que são a via pela qual as outras competências se expressam e desenvolvem, o que justifica que o conhecimento, desenvolvimento e até controle dos aspectos afetivos e motivacionais (em si e nos outros) sejam tão estratégicos para as organizações (GONDIM, MORAIS e BRANTES, 2014).

Segundo Argyris (2001), as pessoas são capazes de aprender a identificar o modo como pensam os que as rodeiam, de reconhecer suas carências, ações indesejáveis e desenvolver aspectos socioemocionais importantes, bem como observar o grupo e contribuir com um aprendizado coletivo. A capacidade das pessoas em compreender o comportamento do outro possibilita empatia e a colaboração (CATANIA, 1999), elementos fundamentais para um ambiente propício ao compartilhamento de experiências e conhecimentos.

Dessa maneira, podemos compreender que a inclusão do desenvolvimento de aspectos socioemocionais nas organizações pode ser uma das estratégias para as empresas aprenderem 


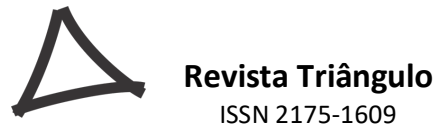

a acolher os fracassos inerentes ao processo de gestão do conhecimento, bem como as dificuldades individuais e do grupo em compartilhar suas experiências e conhecimentos, criando um ambiente favorável para relações mais empáticas e colaborativas, para que novos conhecimentos sejam gerados, circulem e agreguem valor, ampliando o olhar sobre a subjetividade humana e suas histórias.

A partir disso, este estudo pretende trazer luz a questões relevantes ligadas à Gestão do Conhecimento - como os aspectos socioemocionais - e, especificamente, analisar as experiências e opiniões de gestores de pessoas que lideram ou lideraram práticas de Gestão do Conhecimento em organizações. O objetivo principal desta pesquisa é avaliar se as questões socioemocionais estão na pauta desses gestores seja como ferramenta de desenvolvimento ou barreira à Gestão do Conhecimento e se eles estão informados sobre o desenvolvimento de habilidades para facilitar as práticas de Gestão do Conhecimento nas organizações.

A relevância deste estudo está em prover o assunto de pesquisas, já que a Gestão do Conhecimento é vista como uma estratégia valiosa para as organizações e muitas barreiras às suas práticas estão presentes no seu cotidiano (SILVEIRA, 2011). Além disso, o levantamento bibliográfico não apontou estudos brasileiros que tivessem por objetivo principal discutir as relações entre os aspectos socioemocionais e a Gestão do Conhecimento. E, portanto, compreender se as atuações sobre os aspectos socioemocionais que envolvem a Gestão do Conhecimento podem contribuir com o plano de desenvolvimento de suas práticas é a justificativa deste estudo.

\section{MATERIAIS E MÉTODOS}

Adotou-se para esta pesquisa uma abordagem exploratória e descritiva, utilizando elementos tanto da abordagem qualitativa quanto da quantitativa. Além disso, a amostragem deste estudo é do tipo não-probabilístico e por acessibilidade. Segundo Gil (2012), esse tipo de amostra não apresenta fundamentação matemática, mas ainda assim ajuda a trazer luz a assuntos importantes, em condições em que o tempo e o custo são limitados. 


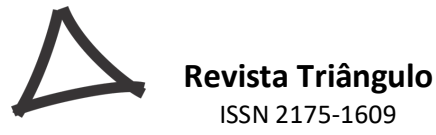

A partir da definição do método de pesquisa, procedeu-se o desenvolvimento de um questionário, ao recrutamento do público-alvo e à coleta de dados. O questionário foi elaborado com 18 questões, sendo 15 de múltipla escolha e 3 abertas. As escalas das questões de múltipla escolha foram escolhidas com base em instrumentos de diagnóstico e de gestão do comportamento organizacional (SIQUEIRA, 2008).

O recrutamento do público-alvo - gestores de pessoas que lideram ou lideraram práticas de Gestão do Conhecimento - foi realizado por meio de divulgação eletrônica, diretamente nos perfis de profissionais com cargos de supervisão, coordenação, gerência e diretoria ou com descrição de experiência em práticas de gestão do conhecimento. Além disso, a pesquisa foi divulgada nas redes sociais da Sociedade Brasileira de Gestão do Conhecimento.

A partir do recrutamento, o questionário foi disponibilizado por meio eletrônico durante 15 dias corridos, entre 15/02/2017 e 03/03/2017. O formulário foi respondido por 44 pessoas.

Ao universo de respondentes, 70\% afirmaram que são responsáveis atualmente pela gestão de práticas de GC (Gestão do Conhecimento) na organização, o que equivale a 31 pessoas, contra $30 \%$, ou seja, 13 pessoas, que responderam não ter atuação presente em Gestão do Conhecimento. Como o objetivo da pesquisa é compreender a atuação dos responsáveis por práticas de conhecimento nas organizações, a análise das questões tomou por base apenas os 31 questionários respondidos por gestores de pessoas que atuam com Gestão do Conhecimento atualmente.

A partir desse crivo, visando aproximar os resultados do objetivo da pesquisa, dos 31 profissionais participantes da pesquisa, 3\% estão na faixa até 25 anos; 32\%, de 26 a 35 anos; $29 \%$, de 36 a 45 anos e $36 \%$ acima de 45 anos. $58 \%$ são do sexo masculino e $42 \%$ do sexo feminino. A grande maioria das pessoas, 77\%, responderam que trabalham com Gestão do Conhecimento há mais de 2 anos.

\section{ANÁLISE DOS DADOS E RESULTADOS}

Sobre a forma como as organizações são estruturadas em Gestão do Conhecimento, 45\% responderam que trabalham em empresas com mais de 500 funcionários e $26 \%$ trabalham em empresas com até 19 funcionários. Em adição, 52\% responderam que há área/departamento/funcionário com dedicação exclusiva à GC, 16\% responderam que não há 


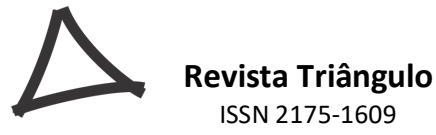

formalização dos responsáveis por essas práticas, $26 \%$ apontaram que não há dedicação exclusiva, mas há responsáveis pelas práticas, e apenas $6 \%$ responderam que não há práticas formais de Gestão do Conhecimento em suas organizações.

O formulário sondou as principais práticas de GC já implantadas por esses gestores. Essa questão permitia selecionar mais de uma prática e obteve os resultados a seguir: em primeiro lugar, base de conhecimento (repositório) com 74\% das seleções; lições aprendidas com $71 \%$; práticas de desenvolvimento humano como coaching e mentoring com $68 \%$; educação corporativa com 58\%; banco de talentos com 39\% e comunidades de prática com $36 \%$.

Em uma questão aberta, os gestores podiam apresentar práticas não incluídas na questão anterior de múltipla escolha. Assim, mencionaram-se também: mapa de competências; mapa de trajetórias; aprendizagem colaborativa; estudos de caso; inovação colaborativa; fóruns de leitura dirigida; trilhas de aprendizagem; rede social corporativa; programa de multiplicadores internos; programas de capacitação; mapeamento de processos e storytelling.

A partir do levantamento das práticas, solicitou-se aos gestores que apontassem as cinco barreiras principais que enfrentam na implantação e prática da gestão do conhecimento. Foram elas: inexistência da cultura de compartilhamento, por $42 \%$ dos gestores; falta de avaliação contínua e sistemática das estratégias de GC, por $42 \%$; desalinhamento entre as práticas de gestão do conhecimento e modelo de gestão da organização, por 39\%; falta de suporte por parte dos gestores, por $39 \%$ e, com o mesmo percentual de $29 \%$ dos gestores, foram apontadas como principais barreiras a falta de uma estrutura formal de apoio para coordenar as iniciativas de GC, a falta de comunicação, "sentimento" do conhecimento como poder e dificuldade de administrar o tempo.

As demais barreiras apontadas foram: resistência do usuário aos sistemas de informação disponíveis (23\%); falta de clareza nos objetivos das ações e práticas (23\%); cultura tecnológica e racional (19\%); falta de percepção de pertencimento à organização (19\%); falta de relação interpessoal (13\%); não compreensão dos objetivos da empresa e das atividades (13\%); medo de punição (13\%); falta de treinamento para a utilização das ferramentas (13\%); falta de confiança (10\%); falta de motivação dos colaboradores (7\%); distância física (7\%); falta de habilidades sociais, como empatia e resolução de problemas (7\%) e ausência de redes sociais $(3 \%)$. 


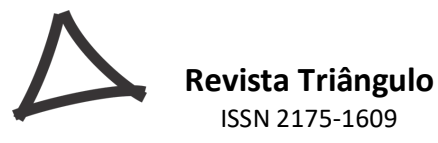

A questão seguinte foi aberta e os gestores puderam incluir barreiras não apontadas na questão de múltipla escolha. As barreiras apresentadas foram: falta de mensuração de ROI dos projetos de GC; conhecimento visto como um ativo exclusivamente individual; falta de entendimento generalizado sobre o papel do conhecimento no negócio e na organização; disputa em tempo e atenção com as atividades do dia a dia; dificuldade em realizar mensuração quantitativa; falta de ferramenta tecnológica; falta de comprometimento dos principais gestores.

Depois de abordadas as barreiras, o questionário aprofundou-se nas questões de aspectos socioemocionais. $74 \%$ desses gestores concordam totalmente que habilidades como fazer e responder a perguntas de forma amigável; dizer "por favor"; manifestar opinião de forma respeitosa; ser empático; falar em público; resolver problemas, tomar decisões e mediar conflitos, impactam as práticas de gestão do conhecimento. $23 \%$ apenas concordam com essa afirmação e 3\% discordam totalmente.

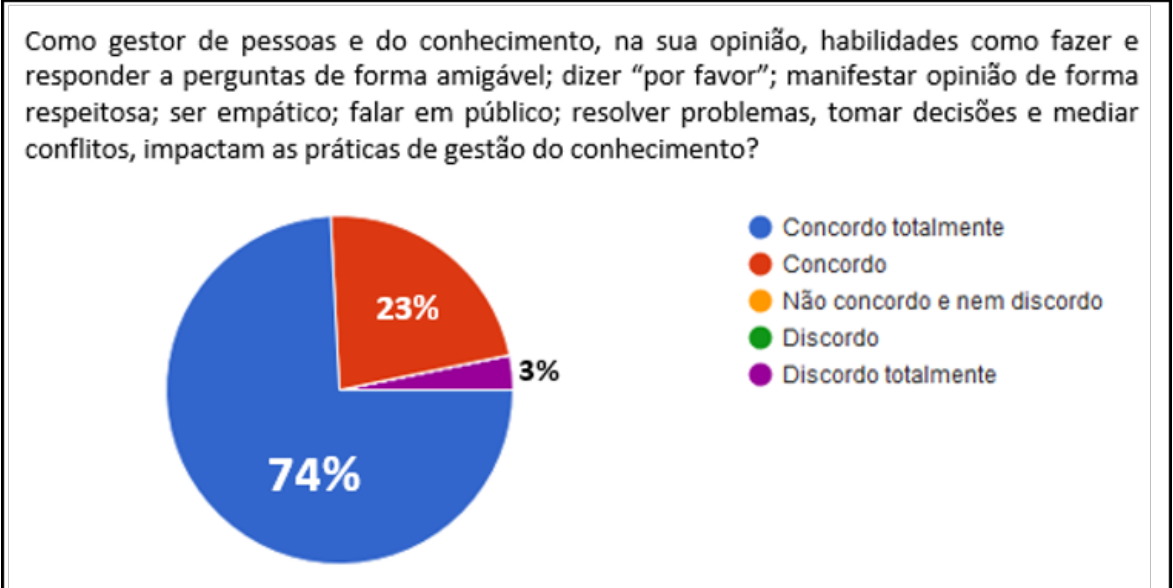

Figura 1 - Distribuição dos gestores quanto à concordância sobre o impacto das habilidades socioemocionais em GC.

Também se questionou se carências de habilidades sociais e emocionais podem prejudicar as práticas de gestão do conhecimento. $45 \%$ concordaram totalmente com a afirmação, 45\% apenas concordaram, $7 \%$ não concordaram e nem discordaram e 3\% discordaram. A partir disso, $45 \%$ dos gestores concordaram totalmente e $42 \%$ apenas concordaram que programas para o desenvolvimento de habilidades sociais e emocionais contribuiriam com as práticas de gestão do conhecimento, enquanto $13 \%$ não concordaram e nem discordaram. Não houve discordância. 


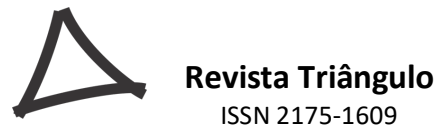

A partir disso, questionou-se se oficinas ou treinamentos direcionados ao desenvolvimento de habilidades socioemocionais já tinham sido considerados ou implantados por esses gestores durante a sua experiência profissional com o objetivo de contribuir com os projetos de gestão do conhecimento. $19 \%$ responderam que tinham implantado programas direcionados ao desenvolvimento dessas habilidades; 39\% tinham considerado esse tipo de projeto, mas nunca o implantaram; 39\% responderam que nunca tiveram acesso a esses projetos; e 3\% já tiveram acesso a esse tipo de programa, mas não têm interesse por ele.

Questionou-se, por fim, o que impede atualmente a implantação de projetos para o desenvolvimento de habilidades socioemocionais como ferramenta para a Gestão do Conhecimento. $32 \%$ apontaram a falta de conhecimento sobre o assunto; $29 \%$ responderam que nada os impede, visto que já executam esses projetos; $26 \%$ apontaram falta de conhecimento sobre o assunto por parte da alta gestão; $10 \%$ nunca ouviram falar desse tipo de projeto; 3\% não têm interesse.

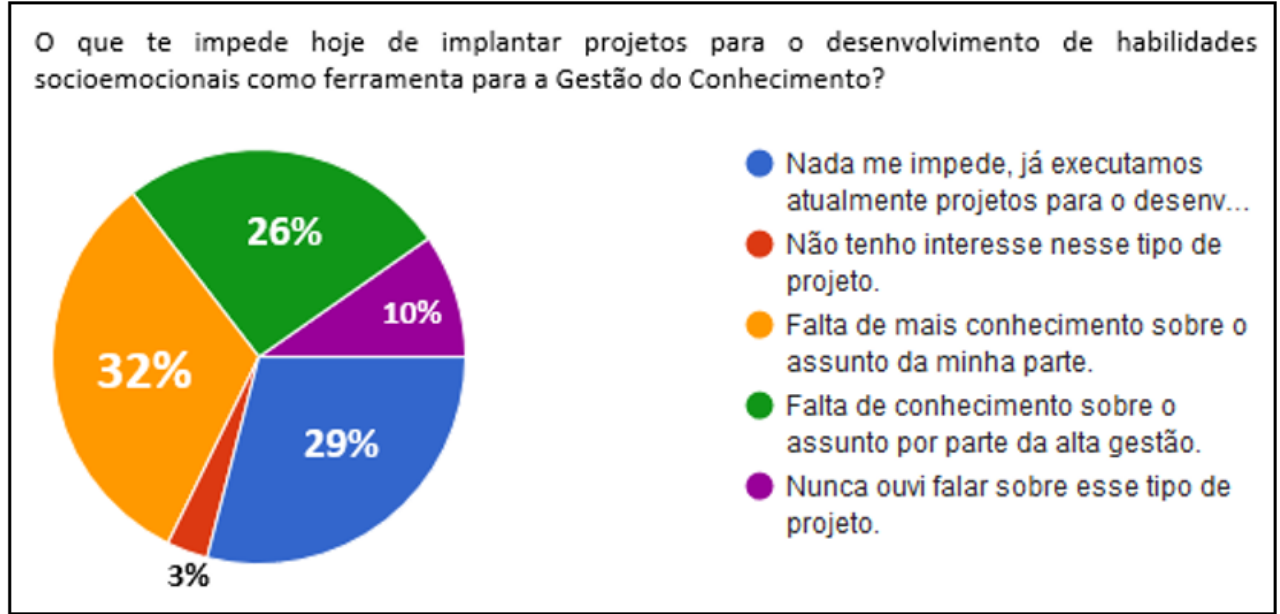

Figura 2 - Distribuição dos gestores quanto ao seu impedimento à implantação da GC.

Uma questão final abriu espaço para que os gestores apontassem algum outro impedimento para realizar tais projetos, do que resultaram as seguintes barreiras: restrições orçamentárias, priorização de outras ações, falta de apoio do RH, falta de apoio da alta direção.

Pelas respostas coletadas, contata-se quanto as questões socioemocionais estão presentes no cotidiano dos gestores de pessoas que praticam gestão do conhecimento. Nesse aspecto reside a maior barreira enfrentada por esses gestores, já que 78\% dos apontamentos mencionaram barreiras relativas as questões socioemocionais e medo de punição $(14,6 \%)$. 
Em adição, 97\% dos gestores questionados responderam que concordam que habilidades sociais simples, como dizer "por favor" ou falar em público, impactam as práticas de gestão do conhecimento. E 97\% igualmente concordam que programas para o desenvolvimento de habilidades sociais e emocionais facilitariam o compartilhamento de informações e contribuiriam com as práticas de gestão do conhecimento. Contudo, apenas 19\% já implantaram esse tipo de programa e os principais impedimentos apontados para não tê-lo feito foram a falta de mais conhecimento sobre o assunto da parte do próprio gestor e a falta de conhecimento sobre o assunto por parte da alta gestão, sinal patente da importância que esse tipo de estudo tem para a prática da gestão do conhecimento nas organizações.

\section{CONSIDERAÇÕES FINAIS}

A dinâmica do capitalismo modificou as relações de trabalho e tem alijando o trabalhador do seu contexto social e produtivo, fragmentando o sujeito e tornando-o peça descartável, impedindo, devido a tanta instabilidade e insegurança, a construção de uma identidade nessa trajetória (GOMES, 2009). Contudo, em um novo contexto, em que o conhecimento dessas pessoas, não mais a "mão de obra" é a principal fonte produtiva, as organizações precisarão rever essa relação e incluir as pessoas em sua completude no sistema ou mesmo no resgate da subjetividade nas relações produtivas, sem o quê, estão condenadas a enfrentar barreiras cada vez maiores à gestão desse conhecimento tão valioso, construídas por mecanismos de defesa, hoje uma das maiores barreiras enfrentadas pelas organizações (SIQUEIRA, 2011).

Dessa forma, a Gestão do Conhecimento estimula um ambiente de trabalho mais favorável ao compartilhamento, disseminação e criação de conhecimentos em todos os níveis, como o objetivo de gerar inovação, valor e vantagem competitiva às organizações, embora caiba à cultura um papel relevante nesse processo de construção e conversão do conhecimento. Contudo, a cultura organizacional precisa aceitar a proposta de um novo ambiente favorável à Gestão do Conhecimento e ultrapassar as barreiras presentes nesse processo (ROSARIO, 2013). Assim, manter a vantagem competitiva em um mercado cada vez mais concorrido é cerne na gestão do conhecimento, o que exige das organizações construir um contexto que 


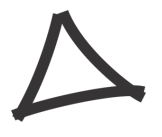

sustente pessoas interagindo sem medo, com espaço para a criatividade (NONAKA e TAKEUCHI, 2005). Portanto, não faz sentido pretender fragmentar o sujeito, exigir e desenvolver nele apenas alguns comportamentos/competências consideradas adequadas a um ambiente de trabalho desalinhado da cultura de compartilhamento e criatividade, desconsiderando seus aspectos subjetivos.

Segundo Nonaka e Takeuchi (2005), o problema dos gestores ocidentais está justamente nesta visão: fazer da empresa uma máquina para processar informações, considerar conhecimento útil apenas aquele que pode ser quantificável e não aproveitar e compartilhar o que há de subjetivo nas pessoas (percepções, intuições e pressentimentos). "A chave de todo o processo está no compromisso pessoal, no sentido de identificação com a empresa e no desempenho de sua missão por parte dos funcionários” (NONAKA e TAKEUCHI, 2005).

Por isso, estudos que tragam luz a questões importantes para a área de Gestão do Conhecimento, como os aspectos subjetivos, sociais e emocionais, e busquem entender as barreiras e dificuldades enfrentadas pelas organizações e profissionais são basilares para a evolução das práticas de GC, em especial quando contribuem com a cultura de compartilhamento para a inovação nas organizações.

Dessa forma, a pesquisa realizada neste estudo com profissionais de Gestão do Conhecimento observou que as questões socioemocionais estão presentes no cotidiano desses gestores, em maioria descrita como barreira à gestão do conhecimento, e que a falta de conhecimento sobre programas de desenvolvimento dessas habilidades, seja por parte do gestor do conhecimento ou da alta gestão da organização, é o principal obstáculo a derrubar para mitigar a barreira da carência de habilidades socioemocionais.

Nem de longe tem essa pesquisa a pretensão de esgotar o tema que propôs. Pelo contrário, seu objetivo é fomentar o espaço de pesquisa e discussão sobre a importância das organizações e profissionais de gestão do conhecimento (sejam de atuação exclusiva ou de outras áreas) para que conheçam as barreiras e aprendam o que fazer para enfrentá-las de modo a diminuí-las ou derrubá-las. Além disso, e principalmente, estabelecer na pauta de Gestão do Conhecimento as questões socioemocionais para contribuir com a sobrevida das empresas que precisam conduzir um ambiente de inter-relação saudável, atrativo e produtivo em termos de conhecimento. Uma pauta subjetiva - convém observar - contribuirá para que os trabalhadores, mesmo em um contexto extremante racional e capitalista, tornem-se mais 


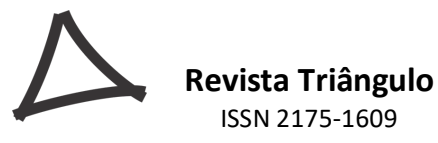

habilidosos na interação com o outro, aumentando dessa forma o campo de troca, a possibilidade de aprendizado, a construção de uma identificação com o trabalho e com a empresa, dando sentido à sua atuação e facilitando a construção de uma trajetória mais autônoma, empoderada e segura.

Por isso, entende-se que esta pesquisa traz múltiplas possibilidades para novos trabalhos sobre o tema. A desinformação dos profissionais do conhecimento sobre programas/projetos que objetivam desenvolver habilidades socioemocionais foi aqui referida e é justificativa fundamental para mais estudos sobre o desenvolvimento de habilidades socioemocionais nas organizações. Em revisão de literatura, foram encontrados diversos estudos sobre a apresentação de questões socioemocionais como barreiras à Gestão do Conhecimento, contudo, nenhum deles sugere ferramentas, métodos, treinamentos, programas ou estudos de casos capazes de servir aos profissionais que buscam mitigar essas barreiras de forma sistemática e fundamentada em métodos científicos, levando-os efetivamente a desenvolver as habilidades socioemocionais tão importantes para a gestão do conhecimento nas organizações.

\section{REFERÊNCIAS}

ABED, A. L. Z. O desenvolvimento das habilidades socioemocionais como caminho para a aprendizagem e o sucesso escolar de alunos da educação básica. São Paulo: Ministério da Educação e Cultura - Conselho Nacional de Educação / UNESCO, 2014. Disponível em $\leq<$ http://educacaosec21.org.br/wp-content/uploads/2013/08/habilidades-

socioemocionais_CNE.pdf $>$. Acesso em: 03 dez. 2016.

ARGYRIS, C. Ensinando pessoas inteligentes a aprender. Gestão do conhecimento, 13. ed. Rio de Janeiro: Elsevier, 2001.

BARROS, J. S; CIUPAK L. F; PAIVA, M. R; TOMAÉL, M. I. Gestão do conhecimento: ações e ferramentas para a superação de barreiras no compartilhamento do conhecimento. PontodeAcesso, v. 4, n. 2, p. 33-57, 2010. Disponível em $\leq$ https://portalseer.ufba.br/index.php/revistaici/article/view/3933 $>$. Acesso em: 03 dez. 2016.

BERLO, D. K. O processo da comunicação (Introdução à teoria e prática). Rio-Lisboa: Fundo de Cultura, 1970.

CAMANHO, R. Produtividade 4.0: a gestão das conversas. Revista ESPM, jul/ago 2016.

CATANIA, C. Aprendizagem: Comportamento, Linguagem e Cognição. 4. ed. Porto Alegre: Artes Médicas Sul, 1999.

\begin{tabular}{l|l|l|l|l|l|l|} 
(C) Rev. Triang. & Uberaba, MG & v.10 & n.2 & p.122-141 & Jul./Dez. 2017 & ISSN 2175-1609 \\
\hline
\end{tabular}


CHIAVENATO, I. Iniciação à teoria das organizações. Barueri: Manole, 2010.

CHOO, C. W. A organização do conhecimento: como as organizações usam a informação para criar significado, construir conhecimento e tomar decisões. São Paulo: SENAC, 2003. Disponível em <https://pt.scribd.com/doc/219865608/CHOO-Chun-Wei-ROCHA-Eliana-aOrganizacao-Do-Conhecimento-Como-as-organizacoes-Usam-a-Informacao-Para-CriarSignificado-Construir-Conhecimento-e>. Acesso em: 03 dez. 2016.

CORRADO, C. A; HAO, J. X.. Brands as Productive Assets: Concepts, Measurement, and Global Trends. Economic Research Working, No. 13, 2014. Disponível em $\leq \mathrm{http}$ //www.wipo.int/publications/en/details.jsp?id=3957\&plang=EN $>$. Acesso em: $03 \mathrm{dez}$. 2016.

DAVENPORT, T. H; PRUSAK, L. Conhecimento empresarial. Rio de Janeiro: Campus, 1998.

DAZA, R. P. Gestão do conhecimento versus gestão das habilidades criativas nas organizações. Revista de Administração, São Paulo, v.38, n.1, p.84-92, jan./fev./mar. 2003. Disponível em $\leq \mathrm{http}$ ://rausp.usp.br/wp-content/uploads/files/V3801084.pdf $>$. Acesso em: 03 dez. 2016.

DEL PRETTE, Z. A. P; DEL PRETTE, A. Psicologia das habilidades sociais: terapia e educação. Petrópolis: Vozes, 1999.

DEL PRETTE, Z. A. P; DEL PRETTE, A. Um sistema de categorias de habilidades sociais educativas. Paideia, v. $18, \quad$ n. $41, \quad$ p. 517-530, 2008. Disponível em $\leq$ http://www.scielo.br/scielo.php?script=sci arttext\&pid=S0103-863X2008000300008>. Acesso em: 03 dez. 2016.

DEL PRETTE, Z. A. P; DEL PRETTE, A. Desenvolvimento interpessoal e educação escolar: o enfoque das habilidades sociais. Temas em psicologia, v. 6, n. 3, p. 217-229, 1998. Disponível em $\quad<\mathrm{http}$ //pepsic.bvsalud.org/scielo.php?script=sci_arttext\&pid=S1413389X1998000300005>. Acesso em: 03 dez. 2016.

FLORIANO, P. R. Sete obstáculos ao compartilhamento do conhecimento e três maneiras de superá-los. Biblioteca Terra Fórum Consultores, 2009. Disponível em $\leq$ http://fgvgc.blogspot.com.br/2010/08/os-sete-obstaculos-ao-compartilhamento.html $>$.

Acesso em: 03 dez. 2016.

GIL, A. C. Métodos e técnicas de pesquisa social. São Paulo: Atlas, 2012.

GOMES, A. F. A. A emergência de uma nova relação homem-trabalho na sociedade atual. Integração, São Paulo, ano XV, n. 59, p. 333-342, out./nov./dez., 2009. Disponível em ftp://ftp.usjt.br/pub/revint/333_59.pdf>. Acesso em: 03 dez. 2016. 
GONDIM, S. M. G; MORAIS, F. A; BRANTES, C. A. A. Competências socioemocionais: fator-chave no desenvolvimento de competências para o trabalho. Revista Psicologia: Organizações e Trabalho, v. 14, n. 4, p. 394-406, 2014. Disponível em $\leq$ http://pepsic.bvsalud.org/scielo.php?pid=S1984-

66572014000400006\&script=sci arttext\&tlng=en>. Acesso em: 03 dez. 2016.

KANT, I. Crítica da Razão Pura. Publicação original em 1781. Disponível em $\leq$ http://br.egroups.com/group/acropolis/>. Acesso em: 03 dez. 2016.

KONDER, Leandro. O que é dialética. $25^{\mathrm{a}}$ ed. São Paulo: Brasiliense, 1981.

LEUCH, V; CARVALHO, H. G; KOVALESKI, J. L. Barreiras culturais à gestão do conhecimento em indústrias de grande porte dos Campos Gerais-no Estado do Paraná: um enfoque na percepção dos funcionários. XXV ENEGEP, v. 29, 2005. Disponível em $\leq$ http://pg.utfpr.edu.br/dirppg/ppgep/ebook/2005/E-book\%202006_artigo\%203.pdf $>$. Acesso em: 03 dez. 2016.

MATTOS, L. A. Gestão estratégica do conhecimento: um estudo de caso. 2010. Tese (Mestrado em Organizações e Desenvolvimento) UNIFAE, Curitiba. Disponível em: $\leq$ http://www2.fae.edu/galeria/getImage/108/137020634680860.pdf $>$. Acesso em: 03 dez. 2016.

MESQUITA, F. S. B. Gestão do conhecimento e criação de valor: um estudo exploratório em empresas brasileiras. 2006. Tese (Doutorado em Administração de Empresas) Fundação Getúlio Vargas, São Paulo. Disponível em: <http://bibliotecadigital.fgv.br/dspace/handle/10438/2571. Acesso em: 13 nov. de 2016.

NONAKA, I; TAKEUCHI, H. Criação de conhecimento na empresa: como as empresas japonesas geram a dinâmica da inovação. 14. ed. Rio de Janeiro: Campus, 2005.

NONAKA, I; TOYAMA, R; HIRATA, T. Managing Flow: Teoria e Casos de Empresas Baseadas no Conhecimento. Porto Alegre: Bookman, 2011.

REBELO, Sabrina et al. Barreiras à implantação da gestão do conhecimento em organizações públicas. In: CONTECSI-International Conference on Information Systems and Technology Management. 2012. p. 2229-2240. Disponível em: $\leq \mathrm{http}: / /$ www.tecsi.fea.usp.br/envio/9contecsi/index.php/envio/article/view/9CONTECSI2012 \%2FPS-584>. Acesso em: 13 nov. de 2016.

SENGE, Peter M. A quinta disciplina: caderno de campo: estratégias e ferramentas para construir uma organização que aprende. Rio de Janeiro: Qualitymark, 1995. 543p.

SENNETT, R. A corrosão do caráter: as consequências pessoais do trabalho no novo capitalismo. Rio de Janeiro: Record, 2015. 
SILVEIRA, R. R. Diretrizes para mitigar as barreiras à implementação da gestão do conhecimento em organizações. 2011. Tese (Doutorado em Engenharia e Gestão do Conhecimento) Programa de Pós-graduação da UFSC, Santa Catarina. Disponível em: $\leq$ http://btd.egc.ufsc.br/wp-content/uploads/2011/06/1-

TESE_Rosana_Rosa_Silveira_PPEGC.pdf $>$. Acesso em: 13 nov. de 2016.

SIQUEIRA, M. M. M. Medidas do comportamento organizacional: ferramentas de diagnóstico e de gestão. Porto Alegre: Artmed, 2008.

SZULANSKI, G. The process of knowledge transfer: a diachronic analysis of stickness. Organizational Behavior and Human Decision Processes, v. 82, n. 1, p. 9-27, 2000. Disponível em: $\quad \leq$ http://citeseerx.ist.psu.edu/viewdoc/summary?doi=10.1.1.202.1378>. Acesso em: 13 nov. de 2016.

TAKEUCHI, H; NONAKA, I. Criação de conhecimento na empresa. Rio de Janeiro: Campus, 1997.

TAKEUCHI, H; NONAKA, I. Gestão do conhecimento. Porto Alegre: Bookman, 2008.

TOUGH, P. Uma questão de caráter: por que a curiosidade e a determinação podem ser mais importantes que a inteligência para uma educação de sucesso. Rio de Janeiro: Intrínseca, 2014.

WILLIAMS, R. L; BUKOWITZ, W. R. Manual de gestão do conhecimento. Porto Alegre: Bookman, 2002. 